\title{
Theoretical Reflections About the Concept of Social Networks
}

\author{
Humberto Elias Garcia Lopes
}

\section{Resumo}

A literatura em teoria organizacional tem dedicado significativa atenção às redes de relacionamento. Contudo, apesar desse foco, é possível notar que ainda persistem muitos problemas teóricos sobre o assunto. Na verdade, pode-se afirmar que lidar com redes de relacionamento implica um dos mais complexos desafios que se colocam diante do pesquisador. Este trabalho tem por objetivo abordar alguns desses problemas teóricos, com o intuito de torná-los menos sujeitos às ambigüidades atuais. Por meio da revisão de parte da literatura organizacional este artigo procura oferecer novos caminhos analíticos para a compreensão da complexidade das redes de relacionamento.

Palavras-chaves: redes de relacionamento; ator; estrutura social atomização; perspectiva normativa; modelo estrutural.

\section{Abstract}

The recent literature on organizational theory has been dedicating a considerable attention to the relationship networks. In spite of this, however, it is possible to notice that there are many theoretical problems concerning this subject matter. In fact, dealing with relationship networks can be considered as one of the most complex challenges to be faced by researchers in organizational theory. This paper intends to contribute to clarify some of those theoretical problems. Through a review of part of the literature on organizational theory this paper tries to propose new analytical paths to understanding the complexity of the relationship networks.

Key words: relationship networks; actor; social structure; atomization; normative perspective; structural model. 


\section{INTRODUCTION}

Nowadays, relationship networks is a subject that has been attracting the attention of Administration. (Burke, Bristor and Rothstein, 1995; Hazleton and Kennan, 2000; Beeby and Booth, 2000). Defined according to Marshall (1988) as they are in principle as a structure formed by actors, either individually or collectively, associated by means of their social connections, relationship networks are being studied in the light of two main lines of thought. The first one primarily concerns managerial practice, in which emphasis is placed on the benefits networks can bring to the efficiency and effectiveness of organizational processes. The other line concerns the academic aspect, whose focus is on the studies that seek to explain the origin, the development and the effects of the networks in the light of a scientific method.

Apart from the prompt surge of interest awakened by curiosity for the theme, there is a second reason for the attention given to networks: sometimes the approaches used by the academy may pose conceptual problems that deserve a more thorough investigation. Maybe the most significant of them all is the very definition of networks, which has become broad enough to envelop distinct phenomena such as economic cooperation agreements between countries, strategic alliances among organizations, interaction between groups, the contacts an individual develops along his life and competitive advantages when securing a job.

The problem with this conceptual flexibility is whether it is, in fact, contributing to a better understanding of networks. According to what was exposed by Sartori (1994), the main objective of a concept is to offer reasonably ordered guidelines for the classification and description of the object in question. So, the author states that if this objective fails to be attained the concept will lose its explanatory power, and consequently its meaning.

Since the interest in the theme presupposes significant and relevant effects on Administration, there will be a need for in-depth studies of a crucial theme, which is the very definition of network. This is one of the most complexes aspects under discussion in the literature at the moment, especially because of the existence of various conceptual perspectives. According to Nohria (1992); Nohria and Eccles (1992); Oliver and Ebers (1998), the main consequence from this was the trivialization of the concepts of network, whereby a profusion of jumbled and contradictory definitions were proposed, creating a further barrier for the researcher to overcome. 
This situation can be explained by the very fragmentation of social sciences, pointed out in Burrel (1998); Morgan (1979). For these authors, different paradigms and concepts, many times mutually extrusive, are used together, thus bringing about theories of poor analytical consistency. Specially in the case of Administration, the situation is by no means different, as shown in the works developed in the area in the last few years. (Alvesson and Deetz, 1998; Bertero, Caldas and Wood, Jr., 1999; Burrel, 1998; Cabral, 1998; Lopes and Bernardes, 2000). What they have in common is their focus on the fragmentation of Administration, an area where different approaches are used as if they formed a homogeneous theoretical body, even when exactly the opposite is demonstrated. As a result, the epistemologically poor scientific production that emerges will hamper the development of a more consistent theoretical basis (Bertero, Caldas and Wood, Jr., 1999).

However, the presence of the subject of networks in academic literature is not followed just by discussions around their concept or application. There are also a considerable number of theories seeking to approach the theme from different angles.

The first consequence of all this is that the chances are that a new theory will be developed based on the contributions made by different areas. As a result, special efforts should be made to integrate distinct constructs, which would probably foster the development of a theory capable of explaining a bigger number of phenomena.

A second consequence is that the theories on network work as a further barrier to the appearance of dogmas. Frequent discussions on the existing theoretical prospects and the construction of new analytical proposals are part of a process that will bring about the permanent threat that some discovery might be contested or even refuted. With this, knowledge is generated, or even altered, on an ongoing basis, according to the fundamental principles of the critical method, as explained by Popper $(1975)^{(1)}$.

If, on the one hand, this diversity of theories has a positive effect on the acquisition of knowledge on the subject, on the other, it has a negative aspect. In an area where there are problems of conceptual application, there is the danger that the presence of a multitude of approaches might be disseminating mistaken conceptions, thus contributing to aggravate the indefinite and contradictory state of affairs.

Another problem lies in the excessive attention given to the sub-theme. The theories on networks vary a lot, allowing the researcher to investigate very specific aspects. In part, this can contribute to a better understanding of a theory, since the variables overlooked in previous studies can now be incorporated to the analysis. 
However, if the researcher focuses his attention exclusively on a very particular aspect of the theory, the location of this study may get lost within the broader picture. The fact is that the researcher would be concentrated on one of the parts to such an extent that he would lose the notion of its connection with the whole. Because of this, the research would lose its strength and end up having very few connections with other findings in the area, no matter how relevant the empiric the results it would come to.

In this light, the aim of this article is to make analytical considerations around the relevant aspects of a specific sort of network, the interpersonal network. However, this will be done without the author losing sight of the connections it has with networks as a whole. Therefore the main aim is to develop an analysis that will make it possible to define the best concept for networks, which will offer the opportunity for the theme to receive more consistent treatment.

\section{IDENTIFYING THEORIES}

Identifying theories may prove a very complex task, especially when it occurs in an area where there are problems with conceptual application, as is the case with theories on networks. Yet, there are papers that seek to fill this gap, by offering analyses that have contributed to the enhanced knowledge of the theme.

With this aim in mind, Nedeva (2000) sought to revise the theories on networks, by grouping them in four distinct categories. The first one being that of social networks, defined as the broadest of all conceptual definitions of network. It is applicable to different levels of analyses, so as to enable the understanding of the patterns of behavior within a social context. According to Nedeva (2000), apart form that, the social network refers both to the structure conceived in terms of social relationship, and the approach on which numerous and significant fields are based, such as stratification, careers, intra- and interorganizational relationships, urban sociology, diffusion of the innovation and health sociology.

As it is possible to see in this definition, the author admits that social networks have a wide scope of application, which allows their use beyond the limits of the organization. Within this category, they are taken as part of the social structure, formed by the relationships between individual and collective actors.

In turn, the author considers that such relationships can be used for interpreting the social behavior of actors. The idea underlying this statement is that relationships help shape the perception individuals have of the reality around them. At the 
same time, this perception equips the actors with patterns of action that they adopt in their interactions. Consequently, at the end of the process, their attitudes will be guided, albeit indirectly, by the relationships built over the years. In summary, Nedeva (2000) affirms that the relationships and behavior of the actors are taken as a function of the social networks, which means that this category should be looked at as action viewed from the point of view of the structure.

The second category is the one that sees the networks as a process, within which they are constantly replicated and altered by the actions of the actors taking part in it. Nedeva (2000) states that one way of thinking in terms of networks is through focusing on their very social construction, which is constantly being replicated and altered, as a result of the action of their actors. This suggests seeing the actors as active agents endowed with purposes, and networks as processes and not merely as structures.

For the author, the central theme, in this group, is the clash between the emergence of networks and the intention of the actors. According to Nedeva (2000), the present debate is divided in two concepts on the theme: firstly, the actors are endowed with intention, which makes them rational. In turn, rationality derives from the economic action, that is, it exists because the actors are offered meager resources and options that have to be combined so as to enhance their utility. One of the ways to do this is by creating networks.

Secondly, the relationships between the actors are developed from more informal interactions. This means that it is not always that an actor goes into a relationship to improve the utility of resources, especially as he may not have a very clear idea of his aims or of the materials made available to him ${ }^{(2)}$. Therefore, his intentions cannot be confined to rational calculation; other factors may be included such as affection, sympathy, influence of third parties, and so forth. Finally, along the years, the actor expands his relationships, by incorporating other actors and, consequently, forming a network.

The third conception derives from the two previous ones, as the formation of a network is seen as the result of the endogenous and exogenous stimuli on the actor. The former refers to the rationality that is inherent to the economic action, that is, the actor tries, in a rational way, to maximize the utility of the resources available to satisfy his needs. The exogenous stimuli, however, are more connected to the second conception, where the actors act according to more flexible rules, without necessarily being engaged in a rational calculation deriving from the unambiguous delimitation of objectives and intentions. The networks are formed by the action of more complex actors, whose patterns of behavior are guided by multiple and involving rules. Sometimes, these rules lead them to build a network 
from a perfectly rational action and, some other times, they will do so in a less intentional or premeditated form. (Reis, 1984).

The third category identified by Nedeva (2000) treats networks as being a prospect, which means considering that any organization can be understood and analyzed in terms of multiple relationships, that is, concerning the perspective of networks, the structure of any organization can be understood and analyzed in terms of multiple relationships, which can be prescribed or emergent.

According to this author, analyzing networks as being perspective means that the focus of organizational studies should not lie on factors such as formal structure or written rules, but rather on the relationship between the actors. They are important because the network built from them is a structure that will supply the parameters for the behavior and actions of its participants. Another advantage mentioned by her, regarding this group, is that its presuppositions can be applied to analyses at any level, micro or macro.

The last category concerns the governance of networks. According to Nedeva (2000), in the first instance, the purpose of these studies is to understand the mechanisms that regulate the integration of the different organizational units. But, in the second instance, the attention is shifted to the way by which this integration affects the behavior of the organization in the market, forcing it to seek to minimize its costs and maximize the return from the transactions it is involved in.

The delimitation of the theories proposed by Nedeva (2000) has a positive aspect, which is the effort to condense the different network perspectives into analytically distinct categories. However, some distinctions made by the author resulted in fuzzy limit lines between one category and the other.

This can be better understood through a more detailed analysis of the author's position on the subject. The first problem was identified in the characterization of social networks. From the very definition proposed by Nedeva (2000), it is clear that she denominates as social any relationship network between actors, either individually or collectively. Up to this point there is really a conceptual delimitation, once it has been established that the term will be applied only to social relationships.

However, if social network is a concept applicable to the relationship between actors, either individually or collectively, then there will be no apparent analytical impediment to denominate as social networks the categories known as process, perspective and governance. So, the application of the term social network would be better placed if it were looked at $a$ priori as a defined restriction, from which all the other categories will be developed. 
Yet, there is a second problem with the analysis conducted by the author. The definition of network as a process has its shortcomings due to the fact that social relationships are dynamic, which is, they are continuously replicated and altered by the actors engaged in them. It is exactly because of this that it is questionable to create an analytical category based on a fact that is inherent to any relationship between actors. As a result, once more there appears the problem of delimitating the categories by departing from those characteristics that are common to all others. However, it is necessary to say that Nedeva (2000) associates the dynamics of social relationships with the issue of whether the actors always act intentionally or not. According to her, this would make a difference in the purposes the network is used for. By acting intentionally, the actors would only be seeking to optimize their preferences, which indicates a merely instrumental pattern of behavior. Otherwise, there would be room for purposes that are not always known, or that, if they are, they will not necessarily be directly associated with optimizing objectives. Przeworski (1988) and Reis (1984) offer a more through discussion on this subject matter.

The third problem found in Nedeva (2000) lies in the category known as network as perspective. The author states that this classification is based on the idea that the focus of organizational studies should be the multiple relationships that take place among the actors, with emphasis on the interactions that they develop inside and outside the boundaries of the organization. They are developed inside and outside the boundaries of the organization. The problem, once more, is that this is a presupposition of any theory of networks, causing the classification based on it to be too broad to form an analytically distinct category. So, it is possible to notice that Nedeva (2000) repeated the problems previously detected. Similar to what occurs in the social networks, perhaps it would be more significant for the theory to say that the relationship between the actors is one of the basic presuppositions of any analysis of networks. It is from this delimitation that the analytic categories were developed.

Despite these limitations regarding governance in her work, Nedeva (2000) has, in fact, dealt with something analytically distinct. By departing from the main presuppositions of the theory, the author established with more rigor the similarities and differences of governance as related to the other approaches.

Another attempt at delimitating the theories of networks, distinctly from the one proposed by Nedeva (2000), was made by Grandori and Soda (1995). In their work, the authors used variables that allowed for a more precise identification of network-related theories. With this aim in mind, they created a typology of eleven theoretical lines. 
The first one of them is the industrial economy, whose main concern are the industrial organizations. According to the authors, it is based on the traditional research on vertical and horizontal integration, although, more recently, its focus has shifted to the issues within the process of internationalization of the economy. Following this line of thought, the variables normally used in the studies measure the efficiency of the network of organizations by means of indicators such as classes of production costs originated from the technologies applied, scale economy and the scope and level of specialization of the activities performed by organization.

The second line is formed by the historical and evolutionist approaches, which emphasize the role played by technology and list the problems associated with costs and learning in the formation of interorganizational networks. More specifically, according to this perspective, the organizations are going through an ongoing process of evolution, whose characteristics stem from the experiences accumulated along their lifetimes. The problem is that this demands the adoption of new technologies, which will bring about further costs and the need for a continuous learning process. From this point on, the networks will appear as structures that the organizations use to bring down such costs and enhance learning through the incorporation of the knowledge brought by the partners involved.

The third line identified is that of organizational economy whose analysis is focused on transaction costs and network governance. The main objective is to discover which factors interfere with the differentiation and coordination of the different areas of the organization and how this helps the organization reduce its transaction costs. Nowadays, this is one of the research lines more frequently found in studies on networks, as shown in Grandori (1997); Jones, Hesterly and Borgatti (1997); Miles and Snow (1992); Provan and Skinner (1989); Pugh and Hickson (1995); Rowley (1997); Turnbull (1997) and Williamson (1975, 1996).

The fourth approach is the negotiation analysis, whose study unit is the bartering of resources and behavior among the organizations. The former are of a material character, involving the exchange of products, services, assets, technologies and so forth. The others involve non-material resources, originated from hands-on experiences, culture of the society, managerial styles personality, among others. The rules applied to the exchange of these two items between organizations are established and controlled by the networks in which they are inserted. For example, if one network is formed to promote, primarily, the deployment of mobile assets, then the negotiation between the organizations will be mainly centered on this aspect. Because of this, the regulation and control mechanisms the network adopts will be adequate to this type of negotiation. The same would occur if emphasis is placed on the exchange of experiences or cultures. 
The fifth line is denominated resources dependency. Here, the basic argument is that the analysis of the relationships between organizations is important for the understanding of the power and dependency relationships between one organization and its partners. With this, the managers will be in a better position to anticipate possible sources of influence of the environment and to adopt strategies that will enable the organization to take advantage of them, thus creating a counterdependency relationship.

The sixth line is the new institutionalism, which has significantly influenced contemporary Sociology, the proof id the impact caused by the works by DiMaggio; Powell (1983); Meyer and Rowan (1991); Powell (1991) and Powell and DiMaggio (1991). This perspective treats the resources dependency as a central theme, but is does not refer only to material assets or transactions, it also includes the legitimization of the organization. The networks, then, appear as central structures, because, when it belongs to one of them, the organization becomes legitimate before the environment it is inserted in. At the same time, when it gets into a relationship with its counterparts, the organization is avoiding its own isolation and monitoring the other organizations, a fact which is crucial if the signs sent by the external environment are to be detected and strategies that will allow it to survive established.

The seventh line is that of institutional embeddedness, where the formation of networks is contingent to bigger social institutions in which the relationships are embedded. The eighth line is what Grandori and Soda (1995) denominate Marxist and extreme studies. Their emphasis is placed on considering the networks, not as mechanisms to promote efficiency and effectiveness in the organization, but as purely power structures, created to reproduce the control of the elites and the dominating classes at an organizational level. This will enable them to control the means of production, as well as the social, political and economic environments. It is also important to point out that this idea of power is not confined to the relationship between networks. Within these structures there may be hierarchies established from the flow of power between the individuals participating in the network (Pfeffer, 1978; Bertero, 1996; Fischer, 1996).

The ninth approach is that of population ecology, where the main argument is that the economic efficiency and effectiveness help select the organizations that will remain in the market. This is delimitated by the niche in which an organization operates and competes with others for the limited resources available. Therefore, those which are more efficient and effective at appropriating these resources will stand more of a chance of surviving. According to Grandori and Soda (1995), for the population ecology, the networks are arrangements that regulate the economic activities in the market. So, if an organization manages to join some network in 
such a way as to use it as a tool to enhance its efficiency and effectiveness in the competition for the resources in its niche, it will substantially increase its chances of surviving market selection, thus proceeding with its activities. On the other hand, failing to join the networks will mean increasing the danger of being eliminated from the competition.

The tenth approach includes the studies on network strategy and management, which, according to Grandori and Soda (1995), make use of many of the theories previously mentioned, without any strict theoretical fidelity to any of them. These studies have focused their attention on the policy of business networks, understood as a strategic alliance between two or more partners, aiming at identifying the competences of the organizations taking part in it. In theoretical terms, in the opinion of the authors, these studies seek to use all possible analytical tools, having as their presupposition the organization as a structure that uses its time striving to improve its situation in the alliance, and, consequently, in the market.

Although Grandori and Soda's (1995) position to this line deserves attention, some restrictions will have to be made. The first one of them is that there is some difficulty in attributing the status of perspective to studies that make use of a considerable variety of theories, as the authors themselves point out. This occurs because the characteristics they pointed out for these studies can be found in researches conducted for other lines.

One such example is the study by Westphal (1999), in which resources dependency is adopted in the classification used until now. He conducted a survey in the United States, involving the boards of directors of the 600 biggest companies in the country. The object was to verify the influence they have on the performance of the companies, since there tends to be a lot of friction about the relationship between board members and managers, which puts the organization in jeopardy. However, results have shown that the boards can give great contribution to the definition of the policies and the elaboration of strategies that will benefit the company.

According to the study, this occurs for two reasons: the first reason is the fact that the members of the boards in the sample surveyed had not developed close relationships of friendship and affectivity with the managers. Therefore, they were capable of establishing more professional and independent parameters when evaluating the administration. The second reason is the function of the boards, which operate as some form of resonance box for the senior management, in charge of defining and implanting policies and strategies. As a result, these policies and strategies have reflected the position of the boards, reducing conflicts and encouraging their members to act as consultants for the managers, by advising them and proposing courses of action. 
As it is possible to note, this study sought to analyze the network formed by the relationships between the boards and the management, without, however, having overlooked the importance of administering the policies of the organizations. Summing up, the tenth line, in fact, consists of a different view on some aspect of the existing theories. Therefore, it cannot be taken as an approach in itself.

The last line identified was that of the theory of social network stems from social psychology. It is focused on the study of the emergence and changes in informal structures, of the limits of the networks, of corporate co-optation and closures and of the patterns of behavior occurring between small companies. As for the methodology used, the researches have been carried out with small groups, with emphasis on the relationship between them.

The problem found is that Grandori and Soda (1995) put this theory down to a very restrictive characteristic, especially as it limits itself to the investigation of small organizations. By the way, this course of action is incoherent with the very concept of social network, which is extremely broad, as already shown in this paper. Most probably, the most adequate course of action in this case would be to maintain the study themes they describe, without confining these themes to small organizations.

Another problem found in their work is that they have failed to specify the level at which the analyses were conducted for some lines, which might generate a certain degree of analytical ambiguity. For example, when they describe the studies carried out on the strategies and management of the networks, they fail to mention that such a line comprises research at both medium and micro levels, as demonstrated in the study by Westphal (1999). Even in other lines, it is possible to se that the characteristics pointed out in the delimitation can be applied to both levels. So, it is important to include the separation of these analytical levels in the analysis by the authors.

Despite these problems, Grandori and Soda (1995) have contributed to a more accurate identification of the approaches to the study of networks. The authors have used items that distinguish the different approaches in a more explicit way than that previously found in Nedeva (2000). However, it is possible to give a step ahead in the delimitation of the theories of networks, thus complementing the analyses conducted by Nedeva (2000) and Grandori and Soda (1995). So, it is important to specify with more clarity some presuppositions and parameters for the theoretical distinction, without underestimating the efforts made by the authors. Much to the contrary, the idea is to improve the way the theories of networks are defined, which will be done in the following paragraphs. 


\section{Making the Distinction Between Theories More Accurate}

The considerations made on the studies by Nedeva (2000) and Grandori and Soda (1995) allow for the identification of some presuppositions and parameters that may help distinguish one theory from the other more accurately. In fact, the idea is to establish more specific evaluation criteria exactly where there are ambiguous points in the works of the authors mentioned. It is, therefore an attempt at upgrading the previous study. This measure is justified because, specially in the case of Grandori and Soda (1995), the effort expended in the classification of the theories led to something of analytical importance, despite some restrictions. Similarly, in Nedeva (2000), relevant aspects that deserve further investigation have been found.

In the first place, it is necessary to concede that delimitating theories of networks can be a very complex task, not only due to the imprecise points mentioned, but also for the very difficulty of establishing with clarity the epistemological limits between the theories in the social sciences area. (Burrel, 1998; Burrel and Morgan, 1979). In the second place, in spite of all that, it is possible to establish some parameters that will enable the researcher to come to a more precise distinction between one theory and another. However, before anything else, the presuppositions that guide the criteria proposed here must be identified.

The first one of them is the nature of the theory. In the case here, it is understood that the interest is placed in the relationship networks between actors, whether individually or collectively. In this way, it is established that attention is confined to social networks, which takes us to the concept by Nedeva (2000).

The second presupposition is that every social relationship is dynamic and is subject to changes effected by the actors involved in it. Even if such relationships are reproduced, this fact does not occur in a very strict form, because there is a possibility that changes will occur.

The third presupposition is that individual actors, at the micro level, are rational. Given the relation of reciprocity they get into with organizations and with broader social structures, this rationality is also reflected in the micro and medium levels. It is crucial to consider that there is no consensus in the social theory concerning the limit line separating the macro, micro and medium levels. The main difficulty is to establish, objectively, where one level ends and the other starts. (Haferkampf, 1987; Alexander and Giesen, 1987; Blau, 1987; Calhoun, 1991; Cook, 1991; Collins, 1987; Gerstein, 1987; March and Olsen, 1989; Schegloff, 1987). 
The fourth presupposition concerns the fact that the relationships under study in a network will have to comply with the persistence criteria, explained by Weber (1968). This means that they will have to be replicated over a time period, not being ephemeral, so that they are relevant for the analysis. Therefore, these relationships will also occur over a period of time and in a determined place.

Based on these presuppositions, it is possible to define parameters that will lead to the establishment of theory categories. The first one is at the analysis level, which is divided in three subcategories: macro: referring to the social structure; medium, concerning micro organizations; and micro regarding individual actors. This classification relies on the development of the social theory of the last decades, when it played a crucial role in the debate on the connections of the levels of analyses.

It is worth pointing out that the discussions around this theme are significantly present in social sciences as a result of the reaction to structural-functionalism, especially in its Parsonian line. According to Marshall (1998), this occurs because Parson's functionalism was often seen as a product of the modern and affluent American society, where the social-structural conflicts have been largely eliminated or seemed to be of a transitory nature, and where there seemed to be some general social cohesion and shared adherence around the values of democracy.

This reaction, in turn, was brought about by an analytical bifurcation: on the one hand, there was the microtheoretical tradition, which, essentially, sought to emphasize the contingent nature of social order and to need to see the individual as the privileged locus of the analysis. As opposed to it, there was an increase in the number of macrotechnical approaches, for which the structures play a fundamental coercive role in determining both the individual and the collective behavior. However, such questionings have proved stronger in their micro version. Besides showing the contrast of the new theories associated with the Parsonian perspective, the approach centered on the individuals gained more importance among the social scientists.

However, it is worth pointing out that this bifurcation, according to which the micro and macro perspectives were regarded as opposed, was steadily phased out. According to Alexander (1987), this situation started when it was proved that it was impossible to sustain unilateral theories, once both the macro and the micro approaches proved to be unsatisfactory in explaining social reality. In turn, it was the awareness that it was impossible to put forward a theory based on the extreme separation of the two analysis level that encouraged the researchers to combine their efforts to link the micro, medium and macro levels, although it may still be possible to identify which of the levels a theory refers to. 
The second parameter, stemming from the previous one, is based on the study carried out by Burt $(1980,1982)$, who was mainly concerned with the development of an integrated approach, in which the actors and the structure act together. According to the author, theoretical delimitation will have to take into account the conception of actor used, which can be atomized, normative or structural. In fact, Burt (1982) states that the first one presupposes that alternative actions are evaluated independently by distinct actors, so that evaluations are carried out without referring to other actors.

This view gets closer to that advocated by classical and neoclassical economies, in which individuals are seen as rational, self-centered and acting in compliance with their own interests, without taking the others into account. What matters here is the maximizing reasoning, aiming at clearly defined satisfaction and desires. Nevertheless, Ritzer (1999) poses that this conception was not accepted without some reluctance. According to him, atomized sociological orientations are focused on actors who take their own decisions. As a whole, their attention is drawn to the actors' personal attributes. The atomized approaches are rejected because they are too microscopic and ignore the relationships between the actors.

It is worth pointing out that the atomized approach is opposed to structuralfunctionalism, which was centered on a macro analysis, in which the remaining levels were ignored or void of in theoretical relevance. So, the larger structures are seen as pre-existent, defining rules, patterns of actions and behavior in society. Yet, in the atomized approaches, the macro level is defined as a mere aggregation: it is the result of the sum of the actions of the individuals, which are modified by them without exerting any influence on them.

As opposed to atomization there is another approach, advocated by Burt (1980), in which the normative perspective is defined by distinct actors within a system and having interdependent interests like the social norms generated by the actors as they socialize with other actors.

The central point of the definition is that it shows that the normative perspective, as opposed to the one mentioned before, suggests that the actors preserve the persistent relationships among themselves, created in the interdependency relationship between its participants, who see in these relationships their opportunity to attain their aims. At the same time, the replication of these relationships, and their persistence along the years, encourage the appearance of norms that are internalized and that guide the actors in their interactions. In other words, what the normative perspective advocates is that the micro level builds the macro level, but, on the other hand, is affected by it, thus creating a retrofed process.

Such observations made have enabled the identification of another feature of 
normative perspective, which is the concern for aspects such as culture and socialization, through which the actors internalize norms and values. In this case, the problem posed is that every analysis is based on the presupposition that the actors preserve some relationship on account of ideas that are shared and materialized by means of internalized norms. Therefore, the point of reference for their behavior are the beliefs common to their groups. So, the idea that actors act to their own benefit rather than to the benefit of the collectivity is unacceptable. In this way, if the atomized approach is mistaken when stating that the actors act in isolation all the time, so is the normative as it considers that they take as their reference internalized norms, born from their interaction with the others.

A third approach identified by Burt (1982), which has had a major impact on the literature on networks, is the structural one, whose difference form the others is in the criterion for the marginal evaluation postulate. The criterion adopted by the structural perspective proposed is that the combination status/role of an actor stems from the division of labor. An actor evaluates the utility of alternative actions, partially, based on his personal situation and that of the others.

What the actor seeks in this definition is to highlight social structure as being the scene where the action occurs. When he refers to the division of labor, Burt (1982) means that it composes the context of the actor and that, because of this, it will be decisive in the way he interprets the world around him and the sequence of his actions. By doing this, this actor will make use of two parallel criteria: the first one being the evaluation of his role and status and the second, the application of this reasoning to the other actors.

A very important characteristic of the structural model is that it seeks to combine the atomized with the normative approach so as to overcome their shortcomings. As posed by Ritzer (1999), Burt (1982) sees his approach as a logical extension to the atomized perspective and an empirically precise restriction of the normative theory.

This extension occurs in the structural model because Burt (1982) admits the rationality of the actor and the direction on which his personal interests will steer his actions. Nevertheless, he attributes a very significant role to the social context in the actor's actions, unlike what is advocated in the atomized perspective. On the other hand, as he states that the other actors also pursue their personal goals, the author is setting limits to normative theory, because however important the social context may be, there are other factors similarly relevant in determining an action. In turn, the individuals have the power to act on the social structure, by altering it and establishing new standards for future actions, thus producing a dynamic and retrofed system. Then, according to Burt (1982), the actors find 
themselves within a social structure. This structure will define their social similarities, which, in turn, will standardize their perception of the advantages to take from the one out of so many alternative actions. At the same time, this social structure hampers the actors' ability to act. The actions eventually taken, therefore, result from a conjunction of actors pursuing their interests to the very limit of their ability, where both interests and actions are standardized by the social structure. Finally, the actions taken under structural social constraints may alter social structure itself, while these alterations will have the potential of creating new constrictions to be faced by the actors within the structure.

It can be seen that the definition the author offers for the structural model reflects his efforts to adopt an integrative approach. In it, it can be noted that the actor and the structure establish a dynamic and reciprocal relationship, in which both sides are able to promote changes, even though these may not occur instantly.

\section{Conclusion}

The presuppositions and parameters described in this article make an important contribution to the analysis of interpersonal networks for three reasons. The first one is that the definition of the presuppositions will help establish the scope of the concept. In the case described here, this will occur when it is defined that only the social networks arouse the interest of the researcher on Administration. The same effect is obtained when it is stated that relationships are dynamic and persistent, and are enacted by rational players.

But besides these presuppositions, a better delimitation for the concept of networks must count on well defined parameters. In this article, two of them were explained: the first one is the analysis level. As it was shown in this article, it is possible to analyze the phenomenon of the networks from a macro, medium and a micro perspective. In the case of interpersonal networks, it will be necessary to access the micro level, which does not mean a return to the radical microsociological approaches, used for marking the reaction against Parson's structural-functionalism. In fact, it is important to bear in mind that the analysis levels are intercalated so that one does not affect the others.

The second parameter dealt with in this article was the conception of the actor. As the networks are the product of the action of individuals, ignoring what sort of actor develops this action will lead to a series of analytical simplifications. So, after revising the atomized and normative conceptions, this paper opted for the structural approach established by Burt (1982). In it, the focus is on the postulate 
of marginal evaluation, according to which the actor evaluates the utility of his action partially in connection with his personal situation and the situation of the others.

However, in spite of the efforts made in this article, it is crucial to recognize that there are still some aspects in the theory of networks that deserve special attention. If this fails to be done, many of the doubts and ambiguities related to this phenomenon will persist. Therefore, one of the challenges posed to researchers in the area is exactly how to delimitate the concept of something as complex and fraught with nuances as relationship networks.

\title{
Notes
}

\begin{abstract}
${ }^{1}$ Two presuppositions have been identified by the author: 1) al the knowledge acquired, all that was learned consist of the alteration (possibly rejection) of some form of knowledge, or disposition, the existed previously and, as a last resource, in innate dispositions; 2) all acquisition of knowledge consists of the improvement of existing knowledge, which changes with the prospects of getting closer to the truth. For further details, see Popper (1975).

${ }^{2}$ It is important to point out that this statement complies with the idea of utility defined by Weber (1997), in which he emphasizes the important role played by subjectivity in the perception of that.
\end{abstract}

\section{REFERENCES}

\section{ALEXANDER, J.;}

GIESEN, B.

From reduction to linkage: the long view of the micro-macro debate. In: ALEXANDER, J. et al. (Orgs). The micro-macro link. Berkeley: University of California, 1987. p. 1-44.

\section{ALVESSON, M.;}

DEETZ, S.

Teoria crítica e abordagens pósmodernas para estudos organizacionais. In: CLEGG, S.;
HARDY, C.; NORD, W. Handbook de estudos organizacionais. São Paulo: Atlas, 1998. p. 227-266.

BEEBY, M.;

BOOTH, C.

Networks and inter-organizational learning: a critical review. The Learning Organization, v. 7, $\mathrm{n}$. 7, p. 75-88, 2000. 
BERTERO, C.

Cultura organizacional e instrumentalização do poder. In: FLEURY, M. T. L.; FISCHER, R. M. Cultura e poder nas organizações. 2.ed. São Paulo: Atlas, 1996.

BERTERO, C.;

CALDAS, M.;

WOOD JR., T.

Produção científica em administração de empresas: provocações, inovações e contribuições para um debate local. Revista de Administração Contemporânea, v. 3, n. 1, p. 147-178, 1999.

BLAU, P.

Contrasting theoretical perspectives. In: ALEXANDER, J. et al. (Orgs). The micromacro link. Berkeley: University of California, 1987. p. 71-85.

\section{BRASLAUSKAS, L.}

Cont(r)atos imediatos. Disponível em: <http://fws.uol.com.br/folio.pgi/ folha99.nfo>Acesso em: 24 maio 1999.

BURKE, R. J.;

BRISTOR, J. M.;

ROTHSTEIN, M. G.

The role of interpersonal networks in women's and men's career development. The International Journal of Career Management, v. 7, n. 3, p. 2532, 1995.
BURREL, G.

Ciência normal, paradigmas, metáforas, discursos e genealogia da análise. In: CLEGG, S.; HARDY, C.; NORD, W. Handbook de estudos organizacionais. São Paulo: Atlas, 1998. p. 439-462.

BURREL, G.;

MORGAN, G.

Sociological paradigms and organizational analysis. London: Heinemann, 1979.

BURT, R.

Models of network structure. Annual Review of Sociology, v. 6, p. 79-141, 1980.

Structural holes: the social structure of competition. Cambridge: Harvard University, 1992.

CABRAL, A. C.

Reflexões sobre a pesquisa nos estudos organizacionais: em busca da superação da supremacia dos enfoques positivistas. In: ENCONTRO ANUAL DA ANPAD, 22., 1998, Foz do Iguaçu. Anais... Rio de Janeiro: ANPAD, 1998. 1 CD-ROM.

\section{CALHOUN, C.}

The problem of identity in collective action. In: HUBER, J. (Ed). Macro-micro linkages in sociology. London: Sage Publications, 1991. p. 51-75. 
COLLINS, R.

Interaction ritual chains, power and property: the micro-macro connection as an empirically based theoretical problem. In: ALEXANDER, J. et al. (Orgs.). The micro-macro link. Berkeley: University of California, 1987.

COOK, K.

The microfoundations of social structure: an exchange perspective. In: HUBER, J. (Ed). Macro-micro linkages in sociology. London: Sage Publications, 1991.

DIMAGGIO, P.;

POWELL, W.

The iron cage revisited: institutional isomorphism and collective rationality in organizational fields. American Sociological Review, v. 48, p. 147-160, Apr. 1983.

FISCHER, R. M.

O círculo do poder: as práticas invisíveis de sujeição nas organizações complexas. In: FLEURY, M. T. L.; FISCHER, R. M. Cultura e poder nas organizações. 2.ed. São Paulo: Atlas, 1996. p. 65-88.

\section{FOLHA DE S.PAULO.}

Profissionais qualificados ainda têm medo de expor dados na rede. Disponível em: <http:// uol.com.br/folio.pgi/fsp2001.nfo/ query=networking/doc/\{@1\}/
hit_he.../hits_only>Acesso em: 29 out. 2001.

\section{GERSTEIN, D.}

To unpack micro and macro: link small with large and part with whole. In: ALEXANDER, J. et al. (Orgs). The micro-macro link. Berkeley: University of California, 1987. p. 86-111.

\section{GRANDORI, A.}

An organizational assessment of interfirm coordination modes. Organization Studies, v. 6, n. 18, p. 897-925, 1997.

GRANDORI, A.;

SODA, G.

Inter-firm networks: antecedents, mechanisms and forms.

Organization Studies, v. 2, n. 6, p. 183-214, 1995.

\section{HAFERKAMPF, $\mathrm{H}$.}

Complexity and behavior structure, planned associations and creation of structure. In: ALEXANDER, J. et al. (Orgs). The micromacro link. Berkeley: University of California, 1987. p. 177-192.

\section{HAZLETON, V.;}

KEENAN, W.

Social capital: reconceptualizing the bottom line. Corporate Communications: An International Journal, v. 5, n. 2, p. 81-86, 2000. 
JONES, C.;

HESTERLY; W.;

BORGATTI, S.

A general theory of network governance: exchange conditions and social mechanisms. Academy of Management Journal, v. 22, n. 4, p. 911-945, 1997.

LOPES, H. E. G.;

BERNARDES, P.

Ampliando a análise da produção científica em administração: $o$ indutivo versus o dedutivo. Belo Horizonte, CEPEAD/UFMG, 2000. Trabalho de disciplina de doutorado. $15 \mathrm{p}$.

MADUREIRA, D.;

MENEZES, B.

Executivos descobrem o poder do mercado oculto. Disponível em: <http:// $2000.246 .213 .5 /$ bnassina/ viewdirect.asp?id_2047692>Acesso em: 29 mar. 2002.

MARCH, J.;

OLSEN, J.

Rediscovering institutions: the organizational basis of politics. New York: The Free Press, 1989.

MENEZES, B.

Contato acadêmico acelera recolocação. Disponível em: <http://2000.246.213.5/bnassina/ viewdirect.asp?id_2047696> Acesso em: 29 out. 2001.
MEYER, J.;

ROWAN, B.

Institutionalized organizations: formal structure as myth and ceremony. In: POWELL, W.; DIMAGGIO, P. (Eds.). The new institutionalism in organizational analysis. Chicago: The University of Chicago, 1991.

MARSHALL, G.

A dictionary of sociology. 2.ed. Oxford: Oxford University, 1998.

MILES, R.;

SNOW, C.

Causes of failure in network organizations. California Management Review, v. 34, n. 4, p. 53-72, Summer 1992.

NAVES, P.

Busca de emprego requer planejamento. Disponível em: <http://www.fws.uol.com.br/ folio> Acesso em: dez. 2000.

NEDEVA, S.

Understanding and managing networks: a guided tour in a terminological jungle. Barcelona: IESE, 2000. 
NOHRIA, N.

Introduction: is a network perspective a useful way of studying organizations? In: NOHRIA, N.; ECCLES, R. (Eds). Networks and organizations: structure, form and action. Boston: Harvard Business School Press, 1992. p. 122.

NOHRIA, N.;

ECCLES, R.

Face-to-face: making network organizations work. In:

(Eds). Networks and organizations: structure, form and action. Boston: Harvard Business School Press, 1992. p. 288-308.

OLIVER, A.;

EBERS, M.

Networking network studies: an analysis of conceptual configurations in the study of interorganizational relationships. Organization Studies, n. 19, v. 4, p. 549-583, 1998.

\section{PFEFFER, J.}

The micropolitics of organizations. In: MARSHALL, R.; MEYER, W. Environments and organizations. San Francisco: Jossey-Bass, 1978. p. 29-50.

POPPER, K.

Conhecimento objetivo: uma abordagem evolucionária. Belo Horizonte: Itatiaia, 1975.
POWELL, W.

Expanding the scope of institutional analysis. In: POWELL, W.; DIMAGGIO, P. (Eds). The new institutionalism in organizational analysis. Chicago: The University of Chicago, 1991. p. 183-203.

POWELL, W.;

DIMAGGIO, P.

Introduction. In: . (Eds).

The new institutionalism in organizational analysis. Chicago: The University of Chicago, 1991. p. 1-38.

PROVAN, K.;

SKINNER, S.

Interorganizational dependence and control as predictors of opportunism in dealer-supplier relations. Academy of Management Journal, v. 32, n. 1, p. 202-212, 1989.

PRZEWORSKI, A.

Marxismo e escolha racional. Revista Brasileira de Ciências Sociais, n. 6, v. 3, p. 5-25, fev. 1988.

\section{PUGH, D.;}

HICKSON, D.

Writers on organizations. 5.ed. Harmondsworth: Penguin Books, 1996. 
REIS, F. W.

Política e racionalidade: problemas de teoria e método de uma sociologia "crítica" da política. Belo Horizonte: UFMG, 1984.

\section{RITZER, G.}

Sociological theory. 5.ed. New York: McGraw-Hill, 1999.

\section{ROWLEY, T.}

Moving beyond dyadic ties: a network theory of stakeholder influences. Academy of Management Journal, v. 22, n. 4, p. 887-910, 1997.

\section{SARTORI, G.}

Comparación y método comparativo. In: SARTORI, G.; MORLINO, L. La comparación en las ciencias sociales. Madrid: Alianza Editorial, 1994. p. 29-49.

SCHEGLOFF, E.

Between micro and macro: contexts and other connections. In: ALEXANDER, J. et al. (Orgs). The micro-macro link. Berkeley: University of California, 1987. p. 207-234.
TURNBULL, S.

Corporate governance: its scope, concerns and theories. Scholarly Research and Theory Papers, v. 5, n. 4, p. 180-205, Oct. 1997.

WEBER, M.

The theory of social and economic organization. New York: The Free Press, 1997.

Economy and society. New York: Bedminster Press, 1968.

WESTPHAL, J.

Collaboration in the boardroom: behavioral and performance consequences of CEO-board social ties. The Academy of Management Journal, v. 42, n. 1, p. 7-24, Feb. 1999.

WILLIAMSON, O.

Transaction cost economics and organization theory. In:

The mechanisms of governance. New York: Oxford University Press, 1996. p. 219249.

Markets and hierarchies: analysis and antitrust implications. New York: The Free Press, 1975. 